\title{
Edge-Punched Cards for Research Notes
}

BY LEWIS E. WEEKS, JR.

ThIS BRIEF NOTE is designed to bring to the attention of scholars the profitable utilization of commercially available edge-punched cards for note taking. Although they have been widely used in bibliographical work, they are not well known or used as yet by academic researchers. Folklorists, however, are beginning to recognize their value in cataloging motifs.

Perhaps the simplest way to illustrate the uses of the punch cards would be to mention a specific experience. The author was recently studying British and American literary criticism in some fifty periodicals; the study dealt with fifteen American authors and covered a twentyyear period. Numbers on the cards were assigned to the following divisions of the outline: British criticism, American criticism, each author, each year of the study, each periodical examined, each work published by each author, and a four division rating which indicated the critic's opinion of the author or work under consideration. Additional divisions could have been made, but the scope of the study and the material available made it unnecessary. Regardless of the way the cards were arranged-and they need not be filed but merely placed in the tray or pile at random as the notes are taken-all of the cards containing material on any one of the topics given above could be selected in a moment. For example, if all of the material on a particular book by Hawthorne were desired, it could be selected directly. If the British criticism had then to be separated from the American, it could be accomplished simply by making another selection with the rod. If the material that had appeared in a particular peri-
Mr. Weeks is Assistant Professor of Liberal Studies in Clarkson College of Technology, Potsdam, New York.

odical was to be selected, it could easily be done; or if the notes were to be arranged chronologically, a simple matter of successive selections with the needle made it possible, all without looking at the note itself. Again, if all of the material devoted to Hawthorne were desired, it could be isolated by a single thrust of the rod, as could any topic or item in a sequence.

Although note taking methods vary with the individual and sometimes with the type of project, most researchers employ some system involving the use of cards. Generally a series of headings taken from the outline of the project and combined with an appropriate indication of the content of each note itself is used on each card; and the cards are thereby grouped systematically under index tabs or dividers of some kind until the writing is begun. The chief problems of such a system are the frequent necessity of cross referring and the difficulty of keeping material in usable and efficient order.

The edge-punched note cards eliminate these problems as well as provide a simple and effective means of selecting material from the file as it is needed. No actual filing is necessary because the selection of any card in the stack is made quite independently of its location.

The system is applicable to any discipline and can be employed on any level of the subject from that of the broadest and simplest of main topics to that of the narrowest of subdivisions. 
The first and most important step and one that is sometimes a bit difficult to accomplish, especially if the material is not to follow a rigidly predetermined pattern, is to prepare an outline in detail and assign a number from the cards to each topic or division. However, changes can be made, values reassigned, and topics added or dropped if material is not available on an anticipated subject or if a different pattern seems more appropriate at a later stage of the research.

The five by eight card, frequently found to be the most convenient size for note taking, has ninety-one numbers that may be assigned to divisions of the outline for direct selection, usually an ample number for most projects. If more divisions are needed, additional numbers in a second row are provided in groups of four, each group permitting up to fourteen classifications or divisions to be added. Obviously the possibilities of selection are more than adequate for almost any conventional undertaking. Around the edge of the card are holes matching the numbers. On any given card, the material in the note determines the holes to be notched out. A quick glance at the master card or the numbered outline indicates the topic or topics that are covered by or related to the note, and holes opposite those numbers are notched out. To select all the material on a given topic or division

\section{Foreign Area Studies}

(Continued from page 296)

a new central library as at Cornell's Olin library, involves both capital outlay and a continuing annual expense.

Also affected by growing area programs is the availability of staff work space, increased reference and circulation work, and the inevitable increase in the number of undergraduate courses in the areas concerned, involving the ob- of the outline, a rod is inserted in the appropriate numbered hole in the stack of cards and is then raised. The cards which drop out because of the previously punched $\mathrm{V}$ notch are those desired.

Because the cards are expensive, costing four or five cents apiece, for notes that require more than both sides of one card, the thrifty scholar can use 4 in. $x$ 6 in. blank tablet sheets, which can readily be fanned slightly on one end, tipped with glue on the fanned edges, and attached to one side of the punched card in such a way as to leave free the selector holes in the edge of the card.

The advantages of this system are chiefly that no cross referring or duplication of notes is necessary because the cross referring and indexing is done by punching the card according to the predetermined plan, either as a note is completed or at the end of a period of note taking when all the notes can be punched at once. If the second method is followed, the conventional headings should probably be made on the card to serve as a guide for punching; or the numbers from the master card or the numbered outline can be jotted down on the card immediately after the note is made. An addition to the advantages already mentioned is the fact that no filing is necessary, for a note is selected by the needle regardless of its location in the stack.

taining of hard-to-get, out-of-print works, journal articles, and necessary duplicate copies of required reading materials.

One gets involved in all these implications when a planned, well-organized program is developed. But what happens when over and above the planned program one has the opportunity of acquiring a large bloc purchase? The processing of such a collection can present problems even to a large library staff with personnel trained and experienced 
in handling area materials. What are the effects of such an acquisition on a library just embarking on an area study program? Can the existing staff manage its processing in a reasonable period of time, or will funds be available to add the necessary help to process the material? If not, the inevitable backlog results. Questions on large block acquisitions include:

1. Does it fit into the long range planning both of the library and the teaching and research staffs?

2. Does it fill an existing gap or is it to be used as the nucleus of a new program?

3. What is required in the way of retrospective purchasing to round out the collection?

4. Can current acquisitions in the field be made without harming established programs?

5. Does the collection contain manuscripts, papers, charts, etc. which might require special facilities for care and preservation, and if so, is the library prepared to handle these special materials?

The recently announced transfer of the Ames library of South Asia to the University of Minnesota where it will be administered as a special unit of the university library is an example of a different, but potentially highly complex block acquisition. This collection of seventyfive thousand items includes books, charts, official papers, and other materials relating to Pakistan, Afghanistan, India, Ceylon, Burma, Tibet, Persia, and Malaya. The interpolation of bibliographical information on a collection of this size into one's catalog could present a substantial problem, to say nothing of the planning which might be required for the coordination of past and future acquisitions with such a substantial collection.

The magnitude of problems incidental to the development of area resources would seem to call for carefully planned programs. Yet Patrick Wilson, ${ }^{13}$ in his survey of South Asian collections, noted the lack of systematic acquisition policies, and Ruggles and Mostecky found ". . . that planned and systematic selection policies, as applied to East European materials . . ., are simply nonexistent in the great majority of research libraries of the United States."14

However, the picture is not completely bleak. The cooperation of librarians and scholars, notably the cooperative efforts of the joint ARL-Farmington Plan-learned societies committees, have made some progress in the following fields:

1. Encouraging descriptive accounts of area resources in individual libraries.

2. The production of bibliographies and research guides.

3. Microfilming projects covering newspapers, archives, and serials.

4. Programs for the reproduction of outof-print books.

5. Cooperative projects including the PL480 programs for the United Arab Republic, India, and Pakistan with the accompanying cooperative and centralized cataloging programs.

6 . The working out of transliteration schemes.

7. The sharing of information via various newsletters and bulletins.

Much more research needs to be done on the problems inherent in the development of non-Western library resourcestheir selection, acquisition, and servicing - and in the training of personnel. Also of primary importance at this time is a study that will explore present practices in the handling of non-Western materials in the major centers with some assessment of the advantages and disadvantages of each. A careful analysis of the experiences of established centers should result in the definition of guidelines applicable to new and changing programs.

${ }^{13}$ Wilson, Survey of South Asian Collections com missioned by Institute of International Studies, University of California, Berkeley (1955).

is Ruggles and Mostecky, op. cit., p. 15. 